\title{
Tolerance to the Humoral and Hemodynamic Effects of Caffeine in Man
}

\author{
David Robertson, Dawn Wade, Robert Workman, Raymond L. Woosley, \\ and John A. OATES, Departments of Medicine and Pharmacology, Vanderbilt \\ Medical Center, Nashville, Tennessee 37232
}

\begin{abstract}
A B S T R A C T Acute caffeine in subjects who do not normally ingest methylxanthines leads to increases in blood pressure, heart rate, plasma epinephrine, plasma norepinephrine, plasma renin activity, and urinary catecholamines. Using a double-blind design, the effects of chronic caffeine administration on these same variables were assessed. Near complete tolerance, in terms of both humoral and hemodynamic variables, developed over the first 1-4 d of caffeine. No longterm effects of caffeine on blood pressure, heart rate, plasma renin activity, plasma catecholamines, or urinary catecholamines could be demonstrated. Discontinuation of caffeine ingestion after $7 \mathrm{~d}$ of administration did not result in a detectable withdrawal phenomenon relating to any of the variables assessed.
\end{abstract}

\section{INTRODUCTION}

Caffeine is probably the most widely consumed drug in Western society. Its pharmacological effects are thus of potentially great importance. Although caffeine exerts effects on many organ systems (1), most data relate to acute effects. Many of these effects are mediated through antagonism of the adenosine receptor (2), but some derive from inhibition of phosphodiesterase (3). Chronic effects of caffeine have received considerably less study. The chronic effects of caffeine in man have been largely extrapolated from acute studies or deduced from epidemiological investigations of coffee drinking. There are obvious limitations to both these approaches.

In a recent acute, double-blind, crossover study, 250 mg caffeine was shown to increase blood pressure and

Dr. Robertson is a Teaching and Research Scholar of the American College of Physicians. Dr. Oates is the Joe and Morris Werthan Professor of Medicine. Address reprint requests to Dr. David Robertson, Vanderbilt Medical Center, Department of Clinical Pharmacology, Nashville, Tenn. 37232.

Received for publication 20 October 1980 and in revised form 5 December 1980. raise plasma renin activity, epinephrine, and norepinephrine levels (4) in subjects who were not coffee or tea drinkers. The increase in blood pressure varied considerably among different individuals, but could increase the risk of cardiovascular disease in susceptible patients if tolerance to it did not develop.

The present investigation was undertaken to determine whether tolerance to these humoral and hemodynamic effects of caffeine develops in man. It seemed important that a double-blind protocol be used and that only young, healthy subjects off all methylxanthines be admitted to the study. To avoid the confounding variable of dietary sodium (5), a metabolic diet was maintained throughout the study. To simulate the customary milieu of caffeine ingestion, the drug or placebo was administered with each meal in a methylxanthine-free barley-based beverage.

Whereas our previous study had examined subjects who never drank coffee, the present investigation was conducted in coffee-drinkers who, for purposes of the experiments, abstained from all methylxanthines for $3 \mathrm{wk}$ before the study. Thus these individuals might be more typical of the relevant population of coffee drinkers than the noncoffee drinkers studied previously.

\section{METHODS}

18 healthy normal subjects ranging in age from 21 to $52 \mathrm{yr}$ were admitted to the study. 12 were female and 6 were male. They had had no coffee, tea, chocolate, or drugs in the $21 \mathrm{~d}$ before the study. Absence of recent caffeine was documented in each subject by undetectable plasma caffeine levels prior to caffeine administration in the protocol.

Subjects were assigned randomly to one of two treatment groups in a double-blind fashion. Subjects in group I received placebo beverage with each meal for the full $14 \mathrm{~d}$ of the study. Subjects in group II received placebo beverage with each meal on the first $3 \mathrm{~d}$ of the study, caffeine beverage with each meal on days 4 through 10, then placebo beverage with each meal again on the final $4 \mathrm{~d}$ of the study. Blood pressure and heart rate in both supine and upright postures were determined twice before and after each meal throughout the entire study. 
Subjects were given a diet containing $150 \mathrm{meq}$ sodium and 80 meq potassium throughout the study. They took all meals in the Elliot V. Newman Clinical Research Center of Vanderbilt University. Special studies were carried out on $2 \mathrm{~d}$ in each subject. On the night of the 3rd study day and the night of the 9th study day, each subject slept in the Clinical Research Center. They were kept flat in bed and given nothing by mouth after midnight. At 6 a.m. and again at 7 a.m. on the following morning, they drank $250 \mathrm{ml}$ of water at room temperature. The mild diuresis thus induced facilitated subsequent urine collections. At 7:30 a.m. an intravenous line of the heparin lock type was placed for venous blood sampling. Beginning at 8 a.m., sphygmomanometric blood pressure and heart rate were determined every $15 \mathrm{~min}$. At 9 a.m, each subject voided and then drank $300 \mathrm{ml}$ of beverage containing either placebo or $250 \mathrm{mg}$ caffeine. The beverage vehicle was prepared by adding 1 tablespoonful of a rye-barley extract available commercially ("Pero," Unifrank Lebensmittelwerke $\mathrm{GmbH}$, Ludwigsburg, Germany) to $300 \mathrm{ml}$ of water at $55^{\circ} \mathrm{C}$. As the subject remained supine, blood samples and blood pressure/heart rate determinations were made at intervals until 1:00 p.m.

Blood samples for plasma renin determination were collected on ice in tubes prepared with $0.3 \mathrm{ml}$ of $10 \%$ EDTA, centrifuged, and separated immediately. Using a method previously described (6), we performed radioimmunoassays for angiontensin I.

Plasma caffeine levels were measured at frequent intervals following the first beverage administration and were repeated at the end of the period of caffeine treatment after the last dose of caffeine. Samples were analyzed with a Waters Associates high-pressure liquid chromatograph (Waters Associates, Inc., Milford, Mass.) consisting of a M600A solvent delivery system, a U6K universal injector, a $\mu$-Bondapak C-18 column, and a $440 \mathrm{UV} / \mathrm{vis}$ detector employing a $280-\mathrm{nm}$ wavelength. The mobile phase, consisting of $500 \mathrm{ml}$ of $2 \%$ acetic acid and $60 \mathrm{ml}$ of acetonitrile, was degassed by vacuum and delivered at a flow rate of $2 \mathrm{ml} / \mathrm{min}$ at ambient temperature. To $0.5 \mathrm{ml}$ of plasma were added $2.0 \mu \mathrm{g}$ of $N$-acetylprocainamide (as internal standard) in $100 \mu \mathrm{l}$ of water, $100 \mu \mathrm{l}$ of $2.0 \mathrm{~N}$ sodium hydroxide, $200 \mu \mathrm{l}$ of water (or standard caffeine solutions for preparing standard curves), and $10 \mathrm{ml}$ of $20 \% \mathrm{~N}$-propanol in chloroform. The resulting mixture was shaken for $5 \mathrm{~min}$ and centrifuged to separate the two phases. The aqueous phase was aspirated and discarded; the organic phase was transferred to a clean vial and blown to dryness at $45^{\circ} \mathrm{C}$ with a gentle stream of dry nitrogen. The residue was injected for quantification. Caffeine concentrations were determined by comparison of peak height ratios of known concentrations of caffeine and $N$-acetylprocainamide added to a methylxanthine-free plasma. The retention times for caffeine and $N$-acetylprocainamide were 6.6 and $7.8 \mathrm{~min}$, respectively (this assay is sensitive to the level of $0.2 \mathrm{~g} / \mathrm{ml}$, and there is no interference from theophylline). The standard curve is linear from 0.2 to $30.0 \mu \mathrm{g} / \mathrm{ml}$. Recovery averaged $91 \pm 4 \%$ (mean $\pm \mathrm{SE}$ ). The coefficient of variation of a patient sample run 15 times on different days was $9 \%$.

Blood and urine samples for measurement of norepinephrine, epinephrine, and dopamine were assayed using a modification of the radioenzymatic method of Passon and Peuler (7). Urinary metanephrine and normetanephrine were assayed using a gas chromatography-mass spectrometry method previously described (8).

In an ancillary study of the blood pressure response to caffeine in coffee drinkers, 16 regular coffee drinkers (three cups daily) were recruited for an acute study. They met all the same criteria for inclusion as the subjects described above except that they continued regular coffee consumption up until $24 \mathrm{~h}$ prior to the study. Humoral variables were not assessed in this study, but blood pressure and heart rate were measured at 15-min intervals following acute administration of $250 \mathrm{mg}$ oral caffeine.

Statistical treatment of the data included analysis of variance and the paired $t$ test, with two-tailed probabilities. Where $P<0.05$, data were considered significant.

\section{RESULTS}

Concentration of caffeine in plasma. There were significant levels of caffeine in plasma within $15 \mathrm{~min}$ of ingestion (Fig. 1). Mean caffeine level was usually maximal by $60 \mathrm{~min}$ after ingestion, but there were large interindividual variations. In one subject the caffeine level was maximal at $15 \mathrm{~min}$, whereas in three subjects, the peak level occurred at $60 \mathrm{~min}$ and in one subject the peak was delayed until $120 \mathrm{~min}$. Peak plasma levels ranged from 3.8 to $14.8 \mu \mathrm{g} / \mathrm{ml}$, with female subjects generally having the higher levels per unit surface area. Caffeine was eliminated with $t_{1 / 2}=10 \mathrm{~h}$.

On the final day of caffeine administration, plasma caffeine levels were again monitored. All subjects had low but detectable caffeine levels at zero time, indicating that plasma caffeine was still significant $15 \mathrm{~h}$ after the caffeine dose with supper on the previous day. Mean initial caffeine level was $2.3 \mu \mathrm{g} / \mathrm{ml}$. The caffeine levels following this final ingestion were parallel to those observed initially, but were consistently 2-3 $\mu \mathrm{g}$ higher (Fig. 1). No significant difference in half-life between day 1 and day 7 was apparent.

Blood pressure. The acute effects of caffeine on blood pressure are illustrated in Fig. 2. There was a very highly significant increase in mean systolic blood pressure during the $2 \mathrm{~h}$ following the initial ingestion of caffeine. The mean increment was $11.2 \pm 2.5 \mathrm{~mm} \mathrm{Hg}$.

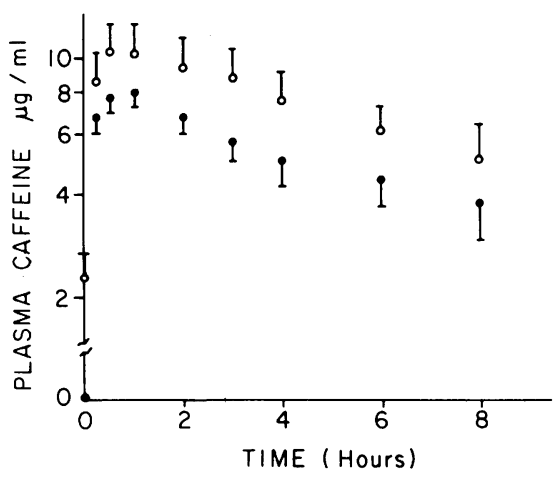

Figure 1 Plasma caffeine levels after oral ingestion of 250 $\mathrm{mg}$ on day 1 of caffeine (O) and day 7 of caffeine (O). Immediately prior to caffeine administration on day 7 , residual plasma caffeine levels averaged $2.3 \mu \mathrm{g} / \mathrm{ml}$ (not shown). 


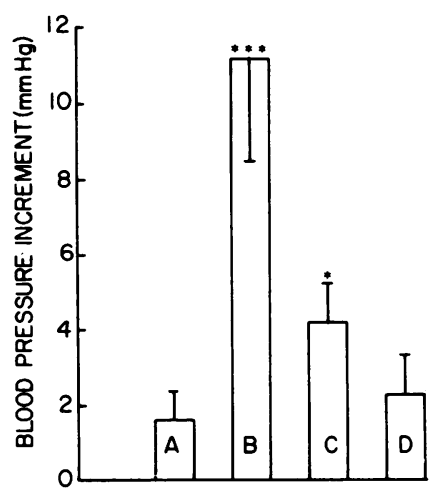

FIGURE 2 Increase in systolic blood pressure during the $2 \mathrm{~h}$ following ingestion of $(\mathrm{A})$ placebo beverage; (B) caffeine $(250$ $\mathrm{mg}$ ) beverage in non-coffee drinkers; (C) caffeine $(250 \mathrm{mg}$ ) beverage in coffee drinkers with initial caffeine levels $1 \mu \mathrm{g} / \mathrm{ml}$; (D) caffeine $(250 \mathrm{mg})$ beverage in coffee drinkers with initial caffeine levels $>1 \mu \mathrm{g} / \mathrm{ml}$. Each value represents the difference between precaffeine sphygmomanometric systolic blood pressure determinations and the mean of eight quarter-hourly blood pressure determinations for each subject. ${ }^{*} P<0.05$. ***P $<0.01$. A, $n=17$; B, $n=17$; C, $n=8 ; \mathrm{D}, n=8$.

In contrast, the acute administration of placebo beverage resulted in a mean systolic blood pressure increment of only $1.8 \pm 0.8 \mathrm{~mm} \mathrm{Hg}$ (not significant).

The effect of chronic caffeine ingestion on blood pressure is illustrated in Fig. 3. Blood pressures of subjects maintained on placebo throughout the $14 \mathrm{~d}$ of the trial are not shown. There was a slight reduction in blood pressure during the first $2 \mathrm{~d}$ of placebo administration, but blood pressure appeared stable after that time. The blood pressure rose significantly on the 1st $d$

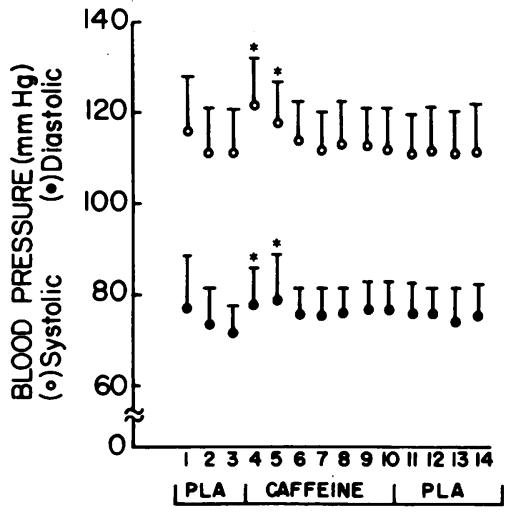

Figure 3 Blood pressure response to caffeine. Numbers on the horizontal axis indicate the day of the study. On days $1-3$, subjects were given placebo beverage with each meal. On days 4-10, they received $250 \mathrm{mg}$ caffeine with each meal. On days 11-14, they again received placebo. Each point represents the mean of six upright and six supine sphygmomanometric systolic $(O)$ and diastolic $(O)$ blood pressure determinations. ${ }^{*} P<0.05$. of caffeine administration. The systolic blood pressure was increased $10 \pm 9 \mathrm{~mm} \mathrm{Hg}$ the day after $250 \mathrm{mg}$ caffeine, with each meal was begun $(P<0.05)$. However, the increase in pressure did not persist. It was still significantly higher than baseline on day 2 of caffeine, but by day 4 it had returned to baseline and remained at this level for the duration of the study. Diastolic blood pressure changes were qualitatively similar but quantitatively only $\sim 60 \%$ as large. In two subjects no significant increase in blood pressure following acute caffeine was observed.

It is noteworthy that discontinuation of caffeine after day 7 did not result in the significant decline in blood pressure which might have been expected if caffeine's effect on pressure had persisted during the week of caffeine treatment.

In ancillary studies of regular coffee drinkers, acute caffeine was administered just $24 \mathrm{~h}$ following discontinuation of usual coffee intake since acute caffeine effects on blood pressure following this period of abstinence seemed more relevant to the usual coffee drinker's situation. Subjects in this group divided into those whose base-line caffeine levels were $>1 \mu \mathrm{g} / \mathrm{ml}$ and those whose base-line level was either undetectable or $<1 \mu \mathrm{g} / \mathrm{ml}$. The increase in systolic blood pressure of $2.2 \pm 1.1 \mathrm{~mm} \mathrm{Hg}$ was not significant in the group with base-line plasma caffeine levels $>1 \mu \mathrm{g} / \mathrm{ml}$ whereas that of $4.2 \pm 1.3 \mathrm{~mm} \mathrm{Hg}$ in those with minimal caffeine levels at baseline was significant. This indicates that abstinence from caffeinated beverages longer than $24 \mathrm{~h}$ is required for the maximal effect of caffeine on blood pressure to be manifest.

There was little effect of chronic caffeine on mean heart rate in this study. Heart rate increased an average of $6 \pm 4$ beats/min after meals associated with placebo and $7 \pm 4$ beats/min after meals associated with caffeine.

Five subjects wore Holter monitors on the day prior to caffeine and on the lst $d$ of caffeine therapy. Because all subjects were healthy, premature beats were rare before caffeine and no significant increase in either premature atrial or premature ventricular contractions was noted in this small sample. In a previous study $250 \mathrm{mg}$ of acute caffeine was associated with paroxysmal atrial tachycardia in a subject who had previously experienced symptoms suggestive of this arrhythmia on four occasions.

Plasma renin activity. Plasma renin activity (PRA) was determined on six occasions immediately before and after the initial and the final dose of caffeine (Fig. 4). The slight upward trend in supine PRA in subjects on placebo during the morning (not shown) was not significant. In contrast, the first dose of caffeine significantly raised PRA from a base-line level of $0.95 \pm 0.18$ to $1.52 \pm 0.27 \mathrm{ng}$ angiotensin $\mathrm{I} / \mathrm{ml}$ per $\mathrm{h}$ by the 


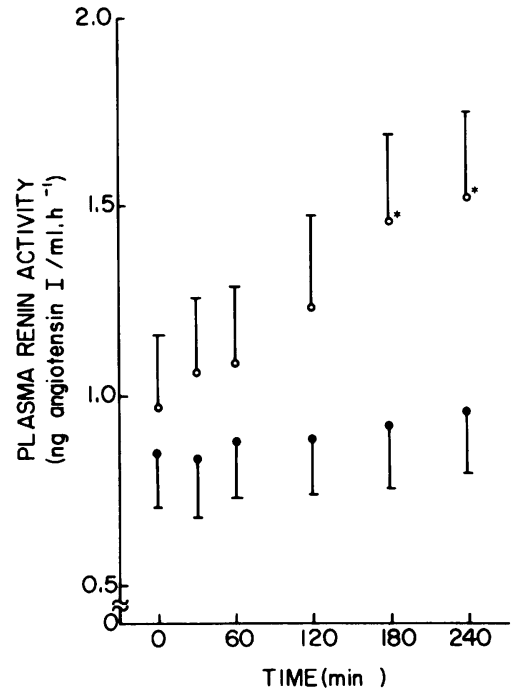

FIGURE 4 The response of plasma renin activity to caffeine. Circles represent the plasma renin activity levels following $250 \mathrm{mg}$ caffeine on the 1st d of active drug while dots represent plasma renin activity levels following $250 \mathrm{mg}$ caffeine on the last day of active drug in the same patients. Note that the base-line plasma renin activity was not higher following $7 \mathrm{~d}$ of caffeine, even though the drug significantly raised plasma renin activity acutely. ${ }^{*} P<0.05$.

4th $\mathrm{h}$ after caffeine. However, by the final day of caffeine administration, the response of PRA to acute caffeine was markedly attenuated; the increase was no longer significant. Moreover, the base-line PRA after
$1 \mathrm{wk}$ of caffeine therapy was not increased; in absolute terms there was a trend for it to be slightly lower. Caffeine did not raise PRA significantly in two of the subjects; the blood pressure response in these two subjects was not less than in the other subjects.

Plasma catecholamines. Following placebo beverage, there was a significant trend for plasma norepinephrine and epinephrine to decline initially, reaching a minimum at about $60 \mathrm{~min}$ and rising back toward baseline during the remainder of the 4 -h period of observation.

The effect of caffeine on plasma catecholamines is illustrated in Fig. 5, where norepinephrine and epinephrine data on the 1st and the final days of caffeine administration are shown. Compared with placebo, acute caffeine raised both norepinephrine and epinephrine. Epinephrine was significantly elevated within $15 \mathrm{~min}$ of caffeine ingestion, whereas norepinephrine was elevated by $30 \mathrm{~min}$. The elevation in plasma epinephrine persisted for $3 \mathrm{~h}$ following caffeine while norepinephrine was still raised when the acute study was terminated at $4 \mathrm{~h}$. Peak plasma norepinephrine and epinephrine levels tended to occur around $3 \mathrm{~h}$ following caffeine.

The response of catecholamines on the final day of caffeine was markedly different (Fig. 5). Both plasma norepinephrine and epinephrine failed to rise significantly. As was the case following placebo, the plasma norepinephine actually declined slightly during the 1 st $h$ after caffeine. On the final day of
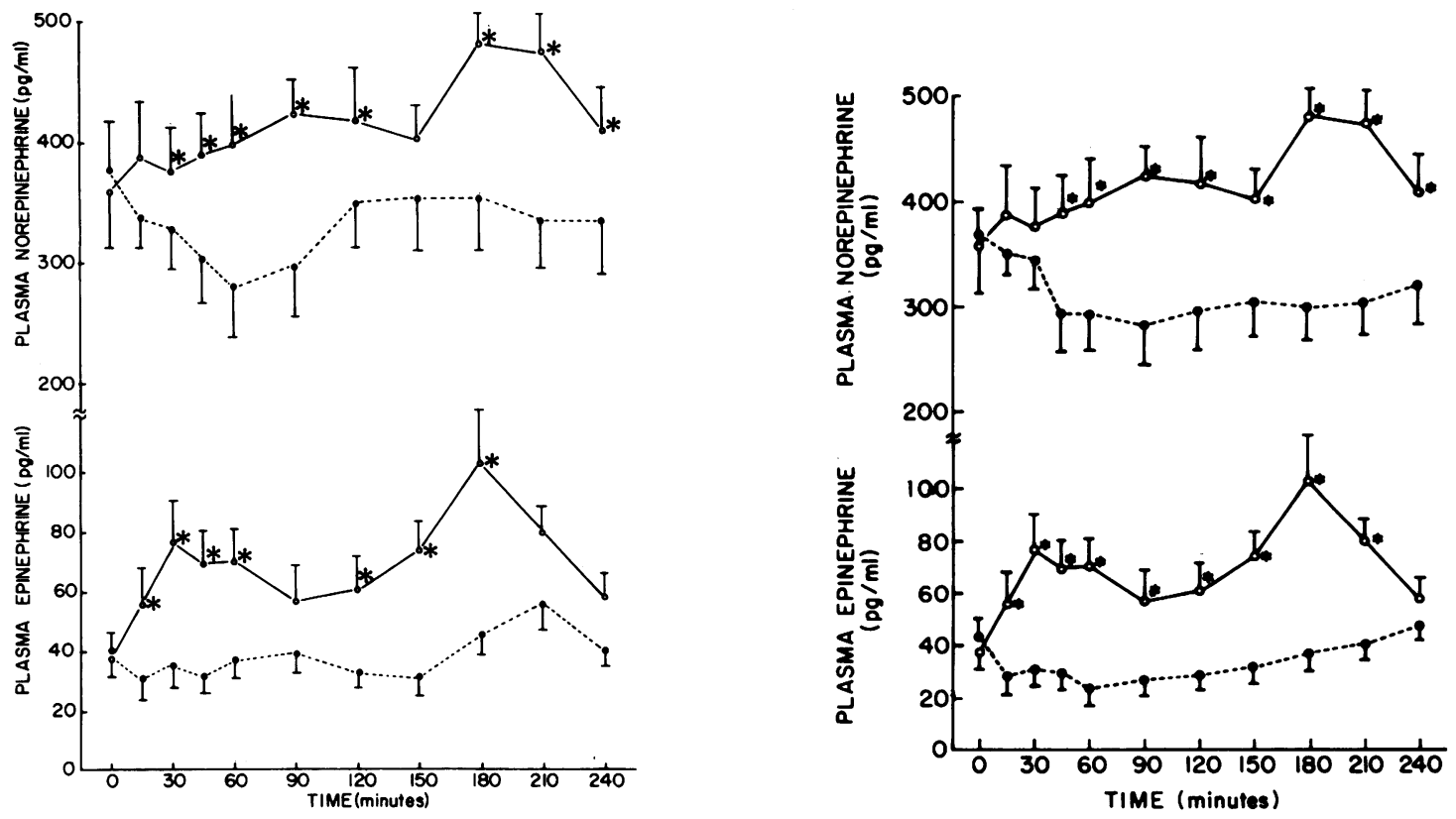

FIGURE 5 (A) The response of plasma epinephrine and norepinephrine to acute ingestion of 250 $\mathrm{mg}$ caffeine on the 1 st $\mathrm{d}$ of caffeine $(O)$ and the final day of caffeine $(O) * P<0.05$. (B) The response of plasma epinephrine and norepinephrine to administration of placebo $(O)$ and $250 \mathrm{mg}$. caffeine (O) on the lst d of the study. ${ }^{*} P<0.05$. 
caffeine, there was no difference in responses of either norepinephrine or epinephrine to caffeine or placebo beverage. As compared with the base-line norepinephrine level, however, the decline in norepinephrine at $60 \mathrm{~min}$ following caffeine was significant on the final day of caffeine.

No significant changes in plasma dopamine were observed.

Urinary catecholamines. Urinary norepinephrine rose from $30 \pm 5 \mu \mathrm{g} / \mathrm{d}$ to $86 \pm 21 \mu \mathrm{g} / \mathrm{d}(P<0.01)$ on the 1 st $d$ of caffeine (Fig. 6). Over the subsequent $3 \mathrm{~d}$ there was a gradual decline of urinary norepinephrine to base-line levels. It remained at that level throughout the final $3 \mathrm{~d}$ of caffeine and during the subsequent $4 \mathrm{~d}$ of placebo; no postcaffeine compensatory drop in urinary norepinephrine was seen.

Urinary epinephrine output rose from $19 \pm 3 \mu \mathrm{g} / \mathrm{d}$ to $34 \pm 6 \mu \mathrm{g} / \mathrm{d}(P<0.01)$ (Fig. 7). As with norepinephrine, the increase was short-lived and declined to base-line levels within 3-4 d. No postcaffeine decline in urinary epinephrine was observed.

Subjects given placebo had a slight increase in norepinephrine ( $36 \pm 5$ to $46 \pm 6 \mu \mathrm{g} / \mathrm{d}$ ) but not epinephrine on day 4 of the study (Fig. 8). This coincided with the intense blood sampling of the acute effects of placebo beverage; this special experimental circumstance may have stressed study subjects. The elevated norepinephrine was only present for $1 \mathrm{~d}$ and was far less than that observed after caffeine.

Urinary dopamine was not altered by either placebo or caffeine.

\section{DISCUSSION}

In a randomized, double-blind crossover study in caffeine-naive subjects, $250 \mathrm{mg}$ oral caffeine was shown to increase blood pressure, respiratory rate, plasma renin activity, and plasma and urinary catecholamines (4). The present investigation was undertaken to

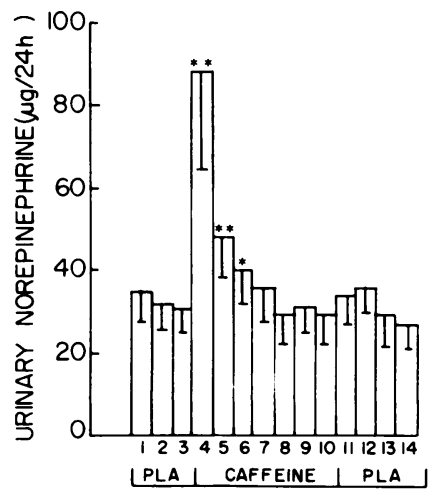

FIGURE 6 Urinary norepinephrine before, during, and after the week of caffeine administration, $250 \mathrm{mg}$ with each meal. Data from subjects receiving placebo throughout the $14 \mathrm{~d}$ of the study are not shown. ${ }^{*} P<0.05 .{ }^{*} P<0.01$.

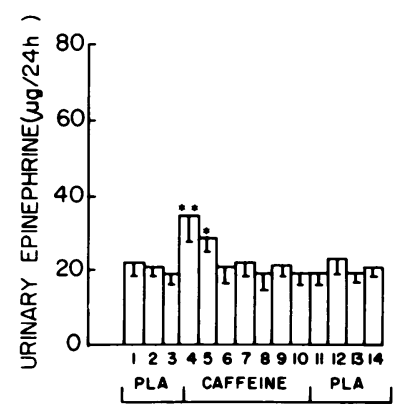

FIGURE 7 Urinary epinephrine before, during, and after the week of caffeine administration, $250 \mathrm{mg}$ with each meal. Data from subjects receiving placebo throughout the $14 \mathrm{~d}$ of the study are not shown. ${ }^{*} P<0.05 .{ }^{* *} P<0.01$.

determine if these acute effects of caffeine were also present during chronic therapy.

It is clear from the present study that the blood pressure increase associated with acute caffeine diminishes as caffeine administration is continued, and is no longer present after day 3 of caffeine when the latter is administered in a dosage of $250 \mathrm{mg}$ three times daily with meals. Tolerance also develops to the effects of caffeine on PRA, plasma catecholamine, and urinary catecholamines. In previous studies, investigators have described tolerance to the diuretic effect (9), the bradycardia and sleep disturbance (10), and the parotid gland secretory effects (11) of caffeine.

In the investigation described, a significant acute rise in blood pressure was confirmed following a 3-wk period of abstinence. To determine whether much briefer periods of abstinence would suffice to enable maximal blood pressure elevation to occur, subjects who had abstained for only $24 \mathrm{~h}$ were challenged with $250 \mathrm{mg}$ acute caffeine. These subjects did not have as great a pressor response as those subjects who had the longer abstinence. The greatest blood pressure response occurred in those subjects with the lowest base-line caffeine levels.

Taken together, these two observations suggest that the abstinence period required for maximal blood pressure response to caffeine is $>1 \mathrm{~d}$ but $<3 \mathrm{wk}$.

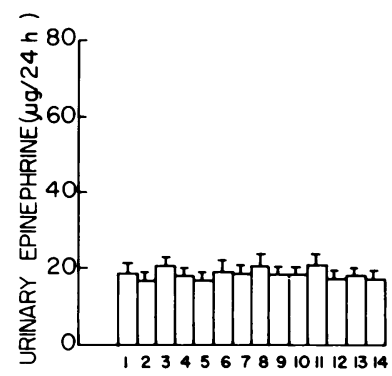

FIGURE 8 Urinary epinephrine levels in control subjects who received placebo beverage throughout the study.

Tolerance to Effects of Caffeine in Humans 
Within the group of coffee drinkers who had $<1 \mu \mathrm{g} / \mathrm{ml}$ caffeine in their blood at baseline, no relation between level of caffeine and blood pressure response to acute caffeine was apparent.

Many studies of methylxanthines have documented a relaxant effect upon vascular smooth muscle tone $(1,20,21)$. Because of this, it seems unlikely that a direct effect of caffeine on vascular resistance is responsible for its pressor effect. However, since myocardial contractility can be enhanced by methylxanthines (22), enhanced cardiac output could be a factor in the observed pressor response.

The increased levels of blood and urinary norepinephrine and epinephrine following caffeine are consistent with generalized stimulation of the sympathetic nervous system with or without a reduction in parasympathetic tone. A direct effect of caffeine on the adrenal medulla to release epinephrine and norepinephrine has been demonstrated in the rat $(12,13)$, and such a mechanism might contribute to the pressor effect of caffeine observed following acute administration in man. However, from hemodynamic data during infusions of epinephrine (14) and norepinephrine (15) in man, it is unlikely that circulating epinephrine levels achieved following caffeine in our studies are sufficiently great to account for the blood presssure increases observed. The sympathetic nervous system activation reflected in these levels of catecholamines could, on the other hand, readily account for the cardiovascular changes documented (5).

It is possible that the increased levels of epinephrine and norepinephrine could be due to a caffeineinduced alteration in catecholamine metabolism. There is evidence that catechol- $O$-methyltransferase can be inhibited by methylxanthines (16), but this is unlikely to account for our findings since parallel increases in urinary normetanephrine and metanephrine in man following caffeine were observed in our acute investigation (4).

Support for central nervous system mediation of the plasma cathecholamine elevation also comes from studies of caffeine administration to rats; adrenal dopamine content increases $80 \% 30$ min after the drug, but this response did not occur in animals with a C-7 spinal cord transection made $24 \mathrm{~h}$ before (17). In the guinea pig, caffeine lowered brainstem norepinephrine levels following administration of the tyrosine hydroxylase inhibitor $\alpha$-methyl- $p$-tyrosine (18). Furthermore, stereotactic injection of caffeine into some sites in the brainstem elicited a systemic pressor effect in the rat (19).

The essentially complete tolerance to the cardiovascular and autonomic effects of caffeine observed in this study, encompassing both hemodynamic and humoral variables, would appear to originate within the central nervous system. Evidence of alterations in the psychotropic effects of caffeine with long-term use has been previously noted $(23,24)$. It is known that input from higher centers feeding into hypothalamic and brainstem nuclei effecting cardiovascular control can significantly modify blood pressure and heart rate in man. Thus, it is possible that caffeine's stimulation of sympathetic function could be mediated by these higher centers and that altered caffeine effects on this input with chronic use might account for the tolerance observed.

The tolerance to the cardiovascular effects of caffeine observed in the present study may explain the apparent disparity between the acute effects of caffeine and the relative absence of deleterious consequences of coffee documented in a number of epidemiological studies. If acute caffeine elevates blood pressure, heart rate, epinephrine, norepinephrine, plasma renin activity and free fatty acids, one might expect to observe an increased incidence of hypertension, cardiovascular disease and death among the population of coffee drinkers. While some studies have suggested a possible link between coffee and myocardial infarction $(25,26)$ and incidence of arrhythmias $(27)$, there is a large body of epidemiological evidence that coffee as an independent risk factor does not increase the incidence of hypertension $(28,29)$, myocardial infarction $(30,31)$, or sudden death. The development of tolerance to the humoral and hemodynamic effects of caffeine may prevent caffeine from being a more consequential risk factor in cardiovascular disease.

\section{ACKNOWLEDGMENT}

This study was supported in part by U. S. Public Health Service grants GM 15431 and HL 14192.

\section{REFERENCES}

1. Eichler, O. 1975. Kaffee und Coffein. Springer-Verlag, Berlin. 2nd edition. 65-320.

2. Fredholm, B. B. 1980. Are methylxanthine effects due to antagonism of endogenous adenosine? Trends Pharmacol Res 1: 129-132.

3. Beavo, J. A., N. L. Rogers, O. B. Crofford, J. G. Hardman, E. W. Sutherland, and E. V. Newman. 1970. Effects of xanthine derivatives on lipolysis and on adenosine 3'5'-monophosphate phosphodiesterase activity. Mol. Pharmacol. 6: 597-603.

4. Robertson, D., J. C. Frölich, R. K. Carr, J. T. Watson, J. W. Hollifield, D. G. Shand, and J. A. Oates. 1978. Effects of caffeine on plasma renin activity, catecholamines and blood pressure. N. Engl. J. Med. 298: 181-186.

5. Robertson, D., G. A. Johnson, R. M. Robertson, A. S. Nies, D. G. Shand, and J. A. Oates. 1979. Comparative assessment of stimuli that release neuronal and adrenomedullary catecholamines in man. Circulation 59: 637643.

6. Carey, R. M., J. G. Douglas, J. R. Schweikert, and G. W. Liddle. 1972. The syndrome of essential hypertension 
and suppressed plasma renin activity: normalization of blood pressure with spironolactone. Arch. Intern. Med. 130: 849-854.

7. Passon, P. G., and J. D. Peuler. 1973. A simplified radiometric assay for plasma norepinephrine and epinephrine. Anal. Biochem. 51: 618-631.

8. Robertson, D., J. T. Watson, R. E. Hill, G. Brilis, E. C. Heath, and F. C. Falkner. 1978. A rapid and sensitive gas chromatography-mass spectrometry method for measurement of urinary metanephrine and normetanephrine. Biomed. Mass Spectrom. 5: 704-708.

9. Eddy, N. B., and A. W. Downs. 1928. Tolerance and crosstolerance in the human subject to the diuretic effect of caffeine, theobromine and theophylline. J. Pharmacol. Exp. Ther. 33: 167-174.

10. Colton, T., R. E. Gosselin, and R. P. Smith. 1968. The tolerance of coffee drinkers to caffeine. Clin. Pharmacol. Ther. 9: 31-39.

11. Winsor, A. L., and E. I. Strongin. 1933. A study of the development of tolerance for caffeinated beverages, J. Exp. Psychol. 16: 725-744.

12. Muscholl, E., G. Kiefer, R. Lindmar. 1969. Die Wirkung von Methylxanthinen anf die Katecholaminspeicherung in Organismus. In Caffein und Andere Methylxanthine. F. Heim and H. P. T. Ammon, editors. Schattaver Stuttgart

13. Berkowitz, B. A., and S. Spector. 1971. Effect of caffeine and theophylline on peripheral catecholamines. Eur.J. Pharmacol. 13: 193-196.

14. Clutter, W. E., D. M. Bier, S. D. Shah, and P. E. Cryer. 1980. Epinephrine plasma metabolic clearance rates and physiologic thresholds for metabolic and hemodynamic actions in man. J. Clin. Invest. 66: 94-101.

15. Fitzgerald, G. A., V. Hossmann, C. A. Hamilton, J. L. Reid, D. S. Davies, and C. T. Dollery. 1979. Interindividual differences in the kinetics of infused norepinephrine in man. Clin. Pharm. Ther. 26: 669-675.

16. Kalsner, S. 1977. Mechanism of potentiation of contractor responses to catecholamines in aortic strips. $\mathrm{Br} . \mathrm{J}$. Pharmacol. 43: 379-388.

17. Snider, S. R., and B. Waldeck. 1974. Increased synthesis of adrenomedullary catecholamines induced by caffeine and theophylline. Naunyn-Schmiedebergs Arch. Pharmacol. 281: 257-260.

18. Berkowitz, B. A., J. H. Tarver, and S. Spector. 1970. Release of norepinephrine in the central nervous system by theophylline and caffeine. Eur. J. Pharmacol. 10: 64-71.

19. Bondaryov, M. G. 1967. The influence of analeptic drugs on the pontine vasomotor center. Prog. Brain Res. 20: 171-186.

20. Anitschkow, S. V. 1923. Uber die Tätigkeit der Gefässe isolierter Finger und Zehen von dem gesunden und Kranken Menschen Z. Exp. Med. 35: 43-75.

21. Somlyo, A. V., and A. P. Somlyo. 1968. Electromechanical and pharmacomechanical coupling in vascular smooth muscle. J. Pharm. Exp. Ther. 159: 129-145.

22. Krop, S. T. 1944. The influence of heart stimulants on the contraction of isolated mammalian cardiac muscle. $J$. Pharmacol. 82: 48-62.

23. Goldstein, A., and S. Kaizer. 1969. Psychotropic effects of caffeine in man. III. A questionnaire survey of coffee drinking and its effects in a group of housewives. Clin. Pharm. Ther. 10: 477-488.

24. Goldstein, A., S. Kaizer, and O. Whitby. 1969. Psychotropic effects of caffeine in man. IV. Quantitative and qualitative differences associated with habituation to coffee. Clin. Pharm. Ther. 10: 489-497.

25. Jick, H., O. S. Miettinen, R. K. Neff, S. Shapiro, O. Heinonen, and D. Slone. 1973. Coffee and myocardial infarction. N. Engl. J. Med. 289: 63-67.

26. Boston Collaborative Drug Surveillance Program. 1972. Coffee drinking and acute myocardial infarction. Lancet. II: $1278-1281$

27. Prineas, R. J., D. R. Jacobs, Jr., R. S. Crow, and H. Blackburn. 1980. Coffee, tea and VPB. J. Chronic Dis. 33: $67-72$.

28. Bertrand, C. A., I. Pomper, G. Hillman, J. G. Duffy, and I. Micheli. 1978. No relation between coffee and blood pressure. N. Engl. J. Med. 299: 315-316.

29. Dawber, T. R., W. B. Kannel, and T. Gordon. 1974. Coffee and cardiovascular disease: observations from the Framingham Study. N. Engl. J. Med. 291: 871-874.

30. Klatsky, A. L., G. D. Friedman, and A. B. Siegelaub. 1973. Coffee drinking prior to acute myocardial infarction. Results from Kaiser-Permanente Epidemiologic Study of Myocardial Infarction. JAMA (J. Am. Med. Assoc.). 226: 540-543.

31. Hennekens, C. H., M. E. Drolette, M. J. Jesse, J. Davies, and G. Hutchison. 1976. Coffee drinking and death due to coronary heart disease. N. Engl. J. Med. 294: 633636 . 